\title{
Genome Editing as a Tool for Fruit Ripening Manipulation
}

\author{
Carmen Martín-Pizarro and David Posé*
}

Laboratorio de Bioquímica y Biotecnología Vegetal, Facultad de Ciencias, Departamento de Biología Molecular y Bioquímica, Instituto de Hortofruticultura Subtropical y Mediterránea, Universidad de Málaga-Consejo Superior de Investigaciones Científicas, Málaga, Spain

\section{OPEN ACCESS}

Edited by:

José Manuel Palma,

Consejo Superior de Investigaciones Científicas (CSIC), Spain

Reviewed by: Hiroshi Ezura, University of Tsukuba, Japan Robert VanBuren, Michigan State University, United States

*Correspondence: David Posé dpose@uma.es

Specialty section: This article was submitted to Plant Breeding, a section of the journal Frontiers in Plant Science

Received: 16 July 2018 Accepted: 06 September 2018 Published: 25 September 2018

Citation: Martín-Pizarro C and Posé D (2018) Genome Editing as a Tool for Fruit Ripening Manipulation.

Front. Plant Sci. 9:1415. doi: 10.3389/fpls.2018.01415
Over the last few years, a series of tools for genome editing have been developed, allowing the introduction of precise changes into plant genomes. These have included Zinc-finger nucleases (ZFNs), transcription activator-like effector nucleases (TALENs), and CRISPR/Cas9, which is so far the most successful and commonly used approach for targeted and stable editing of DNA, due to its ease of use and low cost. CRISPR/Cas9 is now being widely used as a new plant breeding technique to improve commercially relevant crop species. Fruit ripening is a complex and genetically controlled developmental process that is essential for acquiring quality attributes of the fruit. Although the number of studies published to date using genome editing tools to molecularly understand or improve fruit ripening is scarce, in this review we discuss these achievements and how genome editing opens tremendous possibilities not only for functional studies of genes involved in fruit ripening, but also to generate non-transgenic plants with an improved fruit quality.

Keywords: fruit ripening, fruit quality, crops, tomato, genome editing, TALENs, CRISPR/Cas9

\section{INTRODUCTION}

Fruit ripening is a complex and irreversible developmental process that involves numerous metabolic, biochemical, physiological and organoleptic alterations. Among these changes, ripening leads to fruit softening, accumulation of sugars, volatile compounds and pigments, reduction of organic acids, etc., making the fruit more attractive for animal consumption, and therefore, facilitating seed dispersal (Gapper et al., 2013).

Fleshy fruits are classified as climacteric or non-climacteric, depending on whether or not they produce autocatalytic ethylene, respectively. Thus, climacteric fruits such as tomato, apple, avocado, and banana are characterized by an increase in the respiration rate and a burst of ethylene at the onset of ripening (Giovannoni, 2004). In contrast, in non-climacteric fruits, which include strawberry, grape, citrus, and pepper among others, ethylene production remains at low levels and there is no dramatic change in respiration (Symons et al., 2012).

The role of phytohormones and the transcriptional regulation of climacteric and nonclimacteric fruit ripening have been extensively reviewed in the last few years (Gapper et al., 2013; Cherian et al., 2014; Karlova et al., 2014; Kumar et al., 2014). In particular, ethylene perception and signaling have been very well characterized, especially in tomato (Solanum lycopersicum), which is the most studied model system for fruit ripening (Giovannoni, 2001; Barry and Giovannoni, 2007). In contrast, the regulatory network involved in non-climacteric fruit ripening has been much less studied. Nevertheless, it is known that abscisic acid rather than ethylene is essential in the control of ripening in strawberry (Chai et al., 2011; Jia et al., 2011), the established model for non-climacteric fruits. 
Fruit ripening is of major economic importance for agriculture. One of the main challenges for producers is to offer a product at the ripening stage with a good flavor and nutritional value, while also having sufficient shelf life to maintain its quality until it is consumed. This is especially relevant for climacteric fruits highly sensitive to ethylene, and for non-climacteric fruits such as strawberry, which become quickly inedible. Thus, improved ripening and shelf life has been a focus of interest for many scientists in recent decades, using conventional breeding and genetic modification. However, the latter relies on the generation of transgenic plants, which have a very limited commercial use due to the current skepticism of consumers and restrictive government policies. Moreover, transgenic strategies have been based on the modulation of gene expression, which may lead to temporary and/or incomplete knockdown effects, unpredictable off-target effects, and too much background noise (Martin and Caplen, 2007). However, the availability of genome editing tools offers new opportunities to overcome these drawbacks.

\section{THE EMERGENCE OF GENOME-EDITING TECHNOLOGY}

In the past decade, new and powerful approaches have emerged enabling the precise editing of a gene of interest. These approaches are based on the use of nucleases that are targeted to a specific sequence to generate a double-strand break (DSB). DSBs trigger two different repair mechanisms: (i) error-prone non-homologous-end-joining (NHEJ) and (ii) homology-directed repair (HDR). While NHEJ repair results in InDel mutations of variable lengths, $\mathrm{HDR}$ can be used to introduce specific point mutations or a sequence of interest, through recombination supplying an exogenous donor template. To obtain DSBs for genome editing, four major classes of customizable DNA-binding proteins have been engineered so far: meganucleases (Smith et al., 2006), zinc-finger nucleases (ZFNs) (Urnov et al., 2005), transcription activator-like effector nucleases (TALENs) (Christian et al., 2010), and RNA-guided DNA endonuclease Cas9 (Jinek et al., 2012). Meganucleases, ZFN, and TALEN rely on the binding and recognition of the nucleases to specific sequences of DNA. Therefore, these approaches require complex engineering processes to produce custom nucleases that target the sequence of interest. However, methods based on the bacterial CRISPR (clustered regularly interspaced short palindromic repeats)/Cas system have opened up tremendous possibilities, since the specificity does not lie in the endonuclease, but on a simple and cheap design of a single guide RNA (sgRNA) that is complementary to the target sequence.

Despite the enormous number of reported studies using genome editing technology for gene functional studies in plants and crop improvement (Malzahn et al., 2017), only a small handful of studies, summarized in this review (Table 1), have focused on improving or identifying key regulators of fruit ripening as an essential developmental process and an economically relevant trait.

\section{FIRST GENOME EDITING APPROACHES IN TOMATO}

In the case of dicot crops, tomato became the ideal candidate for gene editing because of its several advantages, i.e., (i) diploid and high-quality sequenced genome, (ii) ease of transformation, (Van Eck et al., 2006), and (iii) economic importance, being the fourth most important commercial crop in the world. The first reports on genome editing in tomato appeared in 2014 when CRISPR/Cas9 was applied to effectively perform gene functional analysis by stable root transformation, using Agrobacterium rhizogenes (Ron et al., 2014). This study was followed by two others, where CRISPR/Cas9 and TALENs were applied to generate mutations in complete plants for the first time, in particular for the ARGONAUTE7 (SlAGO7) and PROCERA (PRO) genes, respectively (Brooks et al., 2014; Lor et al., 2014). As in most of the pioneer studies of genome editing in any species, both genes had been functionally characterized already, allowing the functional validation of these new approaches. Particularly, PRO encodes for a DELLA protein that acts as a negative regulator of gibberellin (GA) signaling (Bassel et al., 2008; Jasinski et al., 2008). Lor et al. (2014) characterized the vegetative stage of the TALEN-induced pro mutants, which showed a phenotype consistent with an increased GA response, such as tall and slender plants. Besides their role in plant growth and development, the role of GAs in fruit set (Kumar et al., 2014) and fruit ripening (Dostal and Leopold, 1967) have been widely studied. In fact, a previous report where the spontaneous pro mutant was phenotypically characterized, showed that fruit ripening was significantly delayed and that the Brix index value was higher in the mutant (Carrera et al., 2012), consistent with a higher GA response in these plants. Therefore, it would be expected that fruit ripening was also altered in the TALEN-induced pro mutants, though Lor et al. (2014) did not characterize the fruit phenotype.

Two years later, the ZFNs gene editing tool was applied for the first time in tomato to mutagenize the LEAFY COTYLENDON1LIKE4 (LIL4) gene, which encodes for a subunit of a heterotrimeric transcription factor (Hilioti et al., 2014). Mutation in LIL4 resulted in a pleiotropic phenotype, including fruits with different sizes and shapes, a reduced number of locules, and absence of placenta. Furthermore, fruits with a paler color and slower ripening were obtained (Hilioti et al., 2016), although how LIL4 regulates this processes is still unknown.

\section{RIN - HOW CRISPR/CAS9 CONVERTED A LOSS-OF-FUNCTION INTO A GAIN-OF-FUNCTION MUTATION}

A large number of studies have been focussed in the role of different transcription factors (TFs) involved in the ripening process. One of the most investigated TFs for ripening is RIPENING-INHIBITOR gene (RIN), a member of the SEPALATA $(S E P)$ class of the MADS-box gene family, first discovered half a century ago when a mutation in this locus ( rin) was found to cause a failure to ripen in tomato (Robinson and Tomes, 1968; 
TABLE 1 | List of applications of genome editing technologies to study tomato fruit ripening, and CRISPR/Cas9 in various fruit crop species.

\begin{tabular}{|c|c|c|c|}
\hline Technology & $\begin{array}{l}\text { Gene edited in } \\
\text { tomato }\end{array}$ & Character & Reference \\
\hline TALEN & PROCERA (PRO) & GA metabolism & Lor et al., 2014 \\
\hline CRISPR/Cas9 & $\begin{array}{l}\text { RIPENING-INHIBITOR } \\
(R I N)\end{array}$ & Fruit ripening & Ito et al., 2015, 2017 \\
\hline CRISPR/Cas9 & $\begin{array}{l}\text { SELF-PRUNING } 5 G \\
\text { (SP5G) and } \\
\text { SELF-PRUNING (SP) }\end{array}$ & Photoperiodic response & Soyk et al., 2016 \\
\hline CRISPR/Cas9 & $\begin{array}{l}\text { LONG-NON CODING } \\
\text { RNA (IncRNA1459) }\end{array}$ & Fruit ripening & Li R. et al., 2018 \\
\hline CRISPR/Cas9 & $\begin{array}{l}\text { ORGANELLE } \\
\text { RECOGNITION MOTIF } \\
\text { (SIORRM4) }\end{array}$ & Mitochondrial function & Yang et al., 2017 \\
\hline \multirow[t]{3}{*}{ Grapevine (Vitis vinifera) } & $M L O-7$ & Pathogen resistant & Malnoy et al., 2016 \\
\hline & $I d n D H$ & Tartaric acid biosynthesis & Ren et al., 2016 \\
\hline & VVPDS & Carotenoid biosynthesis & Nakajima et al., 2017 \\
\hline Watermelon (Citrullus lanatus) & CIPDS & Carotenoid biosynthesis & Tian et al., 2016 \\
\hline Cucumber (Cucumis sativus) & elF4E & Virus resistance & Chandrasekaran et al., 2016 \\
\hline Banana (Musa × paradisiaca) & $P D S$ & Carotenoid biosynthesis & Kaur et al., 2018 \\
\hline Kiwifruit (Actinidia Lindl) & AcPDS & Carotenoid biosynthesis & Wang et al., 2018 \\
\hline \multirow[t]{2}{*}{ Sweet orange (Citrus sinensis) } & CsPDS & Carotenoid biosynthesis & Jia and Wang, 2014 \\
\hline & CsLOB1 & Pathogen resistant & Peng et al., 2017 \\
\hline Duncan grapefruit (Citrus $\times$ paradisi) & CsLOB1 & Pathogen resistant & Jia et al., 2016 \\
\hline
\end{tabular}

Vrebalov et al., 2002). RIN is induced early during ripening, and regulates ethylene-dependent and ethylene-independent pathways that promote ripening (Karlova et al., 2014). The effect on ripening of the rin mutation has been commercially exploited as hybrid cultivars (RIN/rin) with an extended shelf life (Kitagawa et al., 2005). Due to the importance and clear phenotype of the rin mutation, the RIN locus has been recently targeted using CRISPR/Cas9 to validate the functionality and inheritance of mutations mediated by this approach in tomato. Ito et al. (2015) designed three CRISPR/Cas9 constructs to mutagenize three different regions within the RIN locus. As expected, CRISPR/Cas9-mediated novel mutations at the RIN locus resulted in an inhibition of fruit ripening at the T0 generation (Ito et al., 2015). However, and contrary to the rin mutant, these CRISPR mutants partially initiated the ripening process, and this was interpreted as the result of the presence of wild-type RIN in the T0 generation. Previously, Vrebalov et al. (2002) generated knockdown RIN plants using RNA interference, resulting in a fruit ripening that was only partially suppressed, in contrast to the green rin mutant phenotype, and interpreted as due to residual expression of RIN. Thus, RIN has been considered so far to function as an essential regulator of ripening, and the models have always been based on the idea that rin was a loss-of-function mutation. However, a recent paper has overturned this model (Ito et al., 2017). Firstly, unlike the rin mutant, homozygous CRISPR/Cas9-mediated knockout rin mutants $(R I N-\mathrm{KO})$ did not fail to ripen, reaching a pale red color. Moreover, a molecular and physiological characterization of these lines showed that most ripening-related parameters were less affected than in the rin mutant. These results suggested that, contrary to what has been considered so far, ripening can be initiated independently of RIN. Furthermore, they also suggested that the rin mutant protein may have gained a new function, as a partial dominant negative mutation that blocks the initiation of ripening. This hypothesis was supported by the fact that rin mutant allele encodes for a in-frame fusion of RIN and Macrocalyx coding sequences (Vrebalov et al., 2002), the latter containing a putative repression motif that might convert rin into a transcriptional repressor. This repressor activity was actually confirmed in vitro (Ito et al., 2017). Consistent with this 
hypothesis, use of CRISPR/Cas9 to generate additional mutations in the rin mutant allele $(\operatorname{rin} \Delta N)$ resulted in fruits that recovered the initiation of ripening, showing a similar phenotype to that of $R I N-\mathrm{KO}$ lines. Furthermore, a molecular and physiological characterization of $\operatorname{rin} \Delta N$ lines showed a partial recovery of most of the ripening markers. Thus, this study proposes that the rin mutant protein would impair the DNA-binding and activation of ripening-related genes by other master regulators such as NONRIPENING (NOR), COLORLESS NONRIPENING (CNR) (Giovannoni, 2004; Manning et al., 2006), or other SEP homologs.

In conclusion, the use of a gene editing approach such as CRISPR/Cas9 has allowed generating alternative knockout alleles, which have changed our current model of fruit ripening, with RIN being necessary to initiate this process, and rin being a loss-of-function mutation. This implies that many results obtained in the past should be reconsidered, and that further experiments should be carried out now that we are closer to defining the actual mechanism.

\section{TARGETING FRUIT TEXTURE}

While RIN/rin hybrid plants are widely used by tomato breeders, the incomplete ripening of these hybrid fruits leads frequently to a poor flavor and a reduced nutritional value. Hence, to modify texture characteristics for an improved shelf life, without reducing tomato organoleptic and nutritional quality, has been a challenge for researchers and breeders for many years. Fruit softening depends on cell-wall modifying proteins such as polygalacturonase, pectin methylesterase, endo- $\beta-(1,4)$ glucanase, $\beta$-galactosidase, and expansin. A number of studies have characterized the effect of silencing the expression of genes encoding these proteins in strawberry (Posé and GarcíaGago, 2011), and tomato (Sheehy et al., 1988; Smith et al., 1990, 1988; Tieman et al., 1992; Hall et al., 1993; Tieman and Handa, 1994; Brummell et al., 1999; Smith, 2002). Silencing of the polygalacturonase gene had no apparent effect on tomato fruit softening (Sheehy et al., 1988; Smith et al., 1990, 1988), but it did affect the firmness of strawberry fruits, which even showed a slightly higher ${ }^{\circ}$ Brix (Quesada et al., 2009). For the rest of the genes, silencing of their expression has had only very small or no detectable effects on both tomato or strawberry fruit ripening (Tieman et al., 1992; Hall et al., 1993; Tieman and Handa, 1994; Brummell et al., 1999; Smith, 2002). However, silencing another cell-wall related protein, the pectate lyase (PL), has been successfully applied for the modulation of fruit firmness in both species. PL silencing increased fruit firmness without changes in color, size, total soluble solids, or metabolites influencing taste and aroma in both strawberry (JiménezBermúdez et al., 2002), and tomato (Uluisik et al., 2016). Particularly in tomato, preliminary analysis of CRISPR/Cas9induced $p l$ mutants has shown an effect on fruit firmness without altering color and soluble solids content (Uluisik et al., 2016). A further characterization would be necessary to confirm that these CRISPR/Cas9 mutant lines maintain other important agronomical characteristics such as aroma, flavor, yield, color, and resistance to pathogens, all required traits for a successful introduction to the market.

\section{TARGETING PHOTOPERIODIC RESPONSE}

An appropriate timing of flowering is not only essential for plant reproductive success but also to optimize yield in agriculture. In a search for the genetic component controlling the different day-length sensitivities regulating flowering in tomato, Soyk and colleagues identified SELF PRUNING 5G (SP5G) as the responsible gene (Soyk et al., 2016). SP5G is a FLOWERING LOCUS T-like gene that works as a floral repressor controlling flowering under long-day conditions (Cao et al., 2015). In this study, the authors generated CRISPR/Cas9-mediated mutations for this gene, obtaining plants that flowered earlier under long-day conditions. Another gene, SELF-PRUNING (SP), is an ortholog of Arabidopsis TERMINAL FLOWER 1 (TFL1) and encodes for another flowering repressor in tomato (Pnueli et al., 1998). The $s p$ mutation revolutionized tomato cultivation since it leads to determinate plants with a synchronized burst of flowering and fruit ripening. In order to obtain faster-flowering and determinate growth plants, Soyk and collaborators used CRISPR/Cas 9 to generate double $s p 5 g s p$ mutants, which showed an earlier flowering burst and an earlier fruit ripening than that of the sp single mutant and the wild-type (Soyk et al., 2016). However, the earlier tomato ripening in the double $s p 5 g s p$ mutant might be caused simply by the earlier flowering time phenotype of these plants. Therefore, further studies on fruit ripening dynamics need to be performed to clarify whether SP5G actually modulates actively this process.

\section{TARGETING POST-TRANSCRIPTIONAL REGULATION}

There are several previous studies demonstrating the importance of post-transcriptional regulation by non-coding RNAs in the control of fruit ripening (Moxon et al., 2008; Zhu et al., 2015; Wang et al., 2016). To investigate further, CRISPR/Cas9 has been employed in two studies to identify and characterize posttranscriptional regulators of tomato fruit ripening.

In plants, long non-coding RNAs (lncRNAs) are important regulators of gene expression, as they interact with DNA, RNA and proteins (Zhu and Wang, 2012). Interestingly, two lncRNAs, lncRNA1459 and lncRNA1840, have been recently associated with tomato fruit ripening (Zhu et al., 2015). To investigate further the role of lncRNA1459 in fruit ripening, this gene was stably knocked-out by Li X. et al. (2018) using CRISPR/Cas9, obtaining CR-lncRNA1459 mutant lines with a delayed fruit ripening. A molecular characterization of this mutant showed that key ripening-related genes involved in lycopene and ethylene biosynthesis, and in signal transduction were downregulated. Consistently, CR- $\ln c R N A 1459$ mutant fruits showed a reduction in lycopene accumulation and an inhibition of ethylene production (Li R. et al., 2018). However, the mechanism and 
target genes of lncRNA1459 in its regulation of fruit ripening still need clarification.

Another post-transcriptional regulation involved in ripening that has been recently explored is RNA editing. In flowering plants, RNA editing by cytidine-to-uridine (C-to-U) conversion is a widespread process that occurs only in plastids and mitochondrial transcripts and plays an important role in developmental processes such as organelle biogenesis, adaptation to environmental changes and signal transduction (Ichinose and Sugita, 2017). In a recent report, Yang et al. (2017) aimed to identify RNA editing factors that might play an essential role in the regulation of tomato fruit ripening. A virus-induced gene silencing (VIGS) assay was performed, targeting 11 RNA editing factor genes putatively related to ripening, positively identifying SlORRM4, which is located in mitochondria (Yang et al., 2017). Consistently, CRISPR/Cas9-mediated stable slorrm4 mutants resulted in a delay of ripening, and in a diminution of the respiratory rates and ethylene production compared with the wild-type. Further molecular characterization showed that slorm 4 mutation results in a down-regulation of genes associated with the Krebs cycle and mitochondrial function, and a decrease in the level of proteins essential for the mitochondrial respiratory chain, supporting the essential role of mitochondria in the regulation of ripening. However, the specific mechanisms linking RNA-editing in mitochondria with ripening requires further investigation.

\section{FUTURE PERSPECTIVES}

Besides ripening, other interesting agronomic traits have been modulated recently in tomato using CRISPR/Cas9, such as parthenocarpy (Klap et al., 2017; Ueta et al., 2017), lycopene content (Li X. et al., 2018), and fruit size, inflorescence branching and plant architecture (Rodríguez-Leal et al., 2017). Especially relevant is the work of Rodríguez-Leal et al. (2017), in which, instead of editing CDS loci, they targeted cis-regulatory elements (CREs) in promoters, obtaining quantitatively different phenotypes (Rodríguez-Leal et al., 2017). CRE mutations are widespread in nature and have notably contributed to crop domestication through the alteration of gene expression levels (Meyer and Purugganan, 2013). Thus, targeting CREs with genome-editing technologies offers the possibility to fine-tune gene expression without the common pleiotropic effects observed in complete loss-of-function mutants, opening the door to enhance variability for important agronomic and quality traits. However, a lack of precise knowledge about functional motifs in CREs hampers the current application of this approach.

In addition to tomato, the CRISPR/Cas9 gene-editing strategy has been successfully applied in several fruit crop species to date, including examples of climacteric ripening species, such as apple (Malnoy et al., 2016; Nishitani et al., 2016), banana (Kaur et al., 2018) and kiwifruit (Wang et al., 2018), and nonclimacteric ripening species, such as sweet orange (Jia and Wang, 2014; Peng et al., 2017), Duncan grapefruit (Jia et al., 2016, 2017), grapevine (Malnoy et al., 2016; Ren et al., 2016; Nakajima et al., 2017), watermelon (Tian et al., 2016), cucumber
(Chandrasekaran et al., 2016), and the woodland (Zhou et al., 2018) and cultivated strawberries (Martín-Pizarro et al., 2018; Table 1). Most of these studies have targeted either the Phytoene Desaturase gene (PDS), or genes to improve pathogen resistance. However, they have opened up the possibility of using CRISPR/Cas9 technology to study or improve fruit ripening in these crops. Among them, strawberry is a species of particular interest because the fast softening of the berries is the main cause of its short shelf life and the source of commercial losses (PerkinsVeazie, 1995). Hence, the successful application of gene editing using the CRISPR/Cas9 approach may provide effective solutions for these postharvest issues.

It is important to highlight that all these studies are based on the generation of new random mutations mediated by the NHEJ mechanism. However, homologous recombination-based gene targeting (GT) allows a more precise genome editing. GT has already been successfully achieved in several crops, including tomato (Čermák et al., 2015; Filler Hayut et al., 2017). In a recent study, GT has been used to extend tomato shelf life by the incorporation of alcobaca (alc) (Yu et al., 2017), an allelic mutation of NOR with a lower impact on fruit quality than nor and rin mutations (Casals et al., 2011), into a wild-type genotype. Despite these successful studies, GT is still a very challenging approach due to its low efficiency. Thus, the optimization of GT in higher plants in general, and in crop species in particular, would provide of a much wider spectrum of possibilities for breeding, allowing the introgression of genes of interest into elite breeding germplasm.

In conclusion, genome editing strategies, especially CRISPR/Cas9 are becoming rapidly more efficient and precise. Their application to the coding sequences of TFs, hormones or

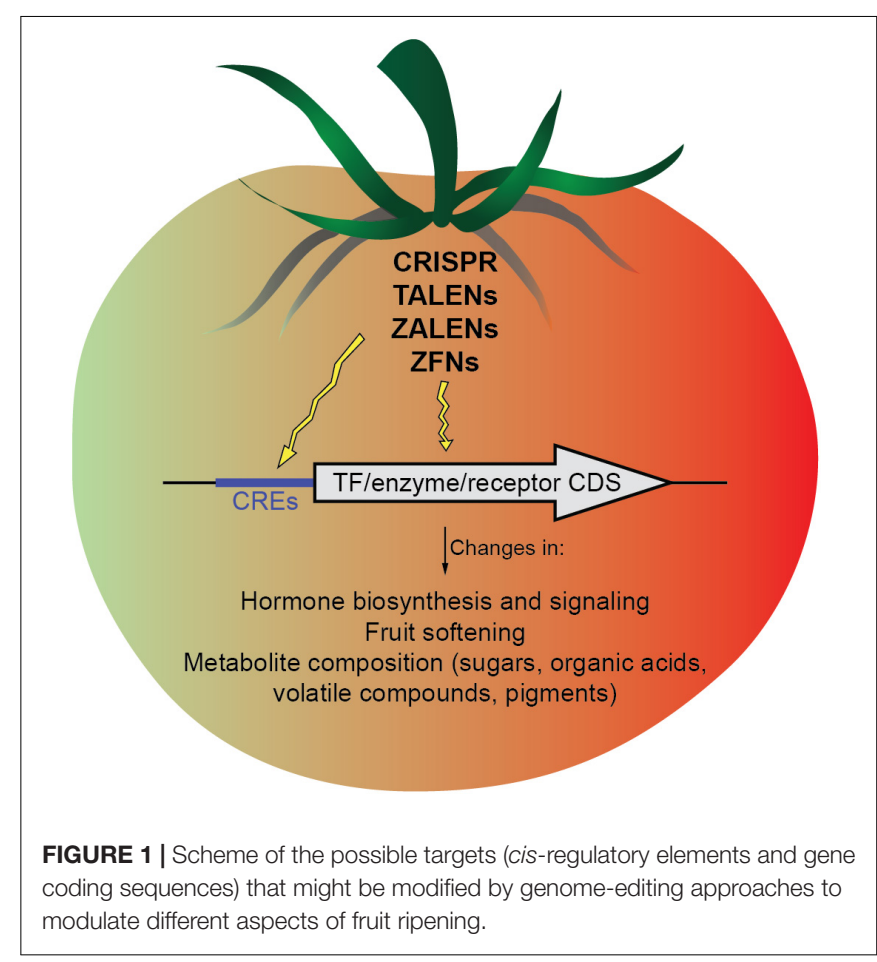


metabolites biosynthetic enzymes, and hormone receptors, or, alternatively to CREs of these genes may allow a more precise fruit ripening modulation (Figure 1). Importantly, genome editing tools have the possibility of removing transgenes through self- or backcrossing, an important advantage compared to traditional approaches for genetic modification. Moreover, preassembled Cas9 protein-gRNA ribonucleoproteins (RNPs) remove the likelihood of inserting recombinant DNA into the host genome. This particular approach has been demonstrated in the protoplasts of several plant species (Woo et al., 2015; Malnoy et al., 2016; Svitashev et al., 2016; Liang et al., 2017) as a strategy that could be potentially operated outside existing GMO regulatory criteria and gain acceptance from consumers. However, the recent decision of the Court of Justice of the European Union is a major setback to innovation in EU agriculture, considering the "process" instead of the "product" and putting crops created using gene-editing techniques under GMO regulations (Directive 2001/18/EC). Hopefully, these

\section{REFERENCES}

Barry, C. S., and Giovannoni, J. J. (2007). Ethylene and fruit ripening. J. Plant Growth Regul. 26, 143-159. doi: 10.1104/pp.104.040998

Bassel, G. W., Mullen, R. T., and Bewley, J. D. (2008). Procera is a putative DELLA mutant in tomato (Solanum lycopersicum): effects on the seed and vegetative plant. J. Exp. Bot. 59, 585-593. doi: 10.1093/jxb/erm354

Brooks, C., Nekrasov, V., Lippman, Z. B., and Van Eck, J. (2014). Efficient gene editing in tomato in the first generation using the clustered regularly interspaced short palindromic repeats/CRISPR-associated9 system. Plant Physiol. 166, 1292-1297. doi: 10.1104/pp.114.247577

Brummell, D., Harpster, M., Civello, P., Palys, J., Bennett, A., and Dunsmuir, P. (1999). Modification of expansin protein abundance in tomato fruit alters softening and cell wall polymer metabolism during ripening. Plant Cell 11, 2203-2216. doi: 10.1105/tpc.11.11.2203

Cao, K., Cui, L., Zhou, X., Ye, L., Zou, Z., and Deng, S. (2015). Four Tomato FLOWERING LOCUS T-like proteins act antagonistically to regulate floral initiation. Front. Plant Sci. 6:1213. doi: 10.3389/fpls.2015.01213

Carrera, E., Ruiz-Rivero, O., Peres, L. E., Atares, A., and García-Martínez, J. L. (2012). Characterization of the procera tomato mutant shows novel functions of the SIDELLA protein in the control of flower morphology, cell division and expansion, and the auxin-signaling pathway during fruitset and development. Plant Physiol. 160, 1581-1596. doi: 10.1104/pp.112. 204552

Casals, J., Cebolla-Cornejo, J., Roselló, S., Beltrán, J., Casañas, F., and Nuez, F. (2011). Long-term postharvest aroma evolution of tomatoes with the alcobaça (alc) mutation. Eur. Food Res. Technol. 233, 331-342.

Chai, Y. M., Jia, H. F., Li, C. L., Dong, Q. H., and Shen, Y. Y. (2011). FaPYR1 is involved in strawberry fruit ripening. J. Exp. Bot. 62, 5079-5089. doi: 10.1093/ jxb/err207

Chandrasekaran, J., Brumin, M., Wolf, D., Leibman, D., Klap, C., Pearlsman, M., et al. (2016). Development of broad virus resistance in non-transgenic cucumber using CRISPR/Cas9 technology. Mol. Plant Pathol. 17, 1140-1153. doi: $10.1111 / \mathrm{mpp} .12375$

Cherian, S., Figueroa, C. R., and Nair, H. (2014). "Movers and shakers" in the regulation of fruit ripening: a cross-dissection of climacteric versus non-climacteric fruit. J. Exp. Bot. 65, 4705-4722. doi: 10.1093/jxb/ eru280

Christian, M., Cermak, T., Doyle, E. L., Schmidt, C., Zhang, F., Hummel, A., et al. (2010). Targeting DNA double-strand breaks with TAL effector nucleases. Genetics 186, 757-761. doi: 10.1534/genetics.110.120717

Čermák, T., Baltes, N. J., Čegan, R., Zhang, Y., and Voytas, D. F. (2015). Highfrequency, precise modification of the tomato genome. Genome Biol. 16:232. doi: 10.1186/s13059-015-0796-9 regulatory decisions will be reconsidered in the future, as there are unquestionable advantages of gene editing to address the challenge of ensuring sufficient food supply for an increasing global population in the current changing climatic conditions.

\section{AUTHOR CONTRIBUTIONS}

All authors conceived and wrote the manuscript.

\section{FUNDING}

This work, CM-P, and DP were supported by the Grant ERC-2014-StG 638134 (European Research Council) (CM-P) and the Ramón y Cajal program RYC-2013-12699 (MINECOUniversidad de Málaga, Spain) (DP).

Dostal, H. C., and Leopold, A. C. (1967). Gibberellin delays ripening of tomatoes. Science 158, 1579-1580. doi: 10.1126/science.158.3808.1579

Filler Hayut, S., Melamed Bessudo, C., and Levy, A. A. (2017). Targeted recombination between homologous chromosomes for precise breeding in tomato. Nat. Commun. 8:15605. doi: 10.1038/ncomms15605

Gapper, N. E., McQuinn, R. P., and Giovannoni, J. J. (2013). Molecular and genetic regulation of fruit ripening. Plant Mol. Biol. 82, 575-591. doi: 10.1007/s11103013-0050-3

Giovannoni, J. (2001). Molecular biology of fruit maturation and ripening. Annu. Rev. Plant Physiol. Plant Mol. Biol. 52, 725-749. doi: 10.1146/annurev.arplant. 52.1.725

Giovannoni, J. J. (2004). Genetic regulation of fruit development and ripening. Plant Cell 16(Suppl.), S170-S180. doi: 10.1105/tpc.019158

Hall, L. N., Tucker, G. A., Smith, C. J. S., Watson, C. F., Seymour, G. B., Bundick, Y., et al. (1993). Antisense inhibition of pectin esterase gene expressionin transgenic tomatoes. Plant J. 3, 121-129. doi: 10.1111/j.1365313X.1993.tb00015.x

Hilioti, Z., Ganopoulos, I., Ajith, S., Bossis, I., and Tsaftaris, A. (2016). A novel arrangement of zinc finger nuclease system for in vivo targeted genome engineering: the tomato LEC1-LIKE4 gene case. Plant Cell Rep. 35, 2241-2255. doi: 10.1007/s00299-016-2031-x

Hilioti, Z., Ganopoulos, I., Bossis, I., and Tsaftaris, A. (2014). LEC1-LIKE paralog transcription factor: how to survive extinction and fit in NF-Y protein complex. Gene 543, 220-233. doi: 10.1016/j.gene.2014.04.019

Ichinose, M., and Sugita, M. (2017). RNA editing and its molecular mechanism in plant organelles. Genes 8:5.

Ito, Y., Nishizawa-Yokoi, A., Endo, M., Mikami, M., Shima, Y., Nakamura, N., et al. (2017). Re-evaluation of the rin mutation and the role of RIN in the induction of tomato ripening. Nat. Plants 3, 866-874. doi: 10.1038/s41477-0170041-5

Ito, Y., Nishizawa-Yokoi, A., Endo, M., Mikami, M., and Toki, S. (2015). CRISPR/Cas9-mediated mutagenesis of the RIN locus that regulates tomato fruit ripening. Biochem. Biophys. Res. Commun. 467, 76-82. doi: 10.1016/j.bbrc. 2015.09.117

Jasinski, S., Tattersall, A., Piazza, P., Hay, A., Martínez-García, J. F., Schmitz, G., et al. (2008). PROCERA encodes a DELLA protein that mediates control of dissected leaf form in tomato. Plant J. 56, 603-612. doi: 10.1111/j.1365-313X. 2008.03628.x

Jia, H., Orbović, V., Jones, J. B., and Wang, N. (2016). Modification of the PthA4 effector binding elements in Type I CsLOB1 promoter using Cas9/sgRNA to produce transgenic Duncan grapefruit alleviating Xcc $\Delta$ pthA4:dCsLOB1.3 infection. Plant Biotechnol. J. 14, 1291-1301. doi: 10.1111/pbi.12495

Jia, H., and Wang, N. (2014). Targeted genome editing of sweet orange using Cas9/sgRNA. PLoS One 9:e93806. doi: 10.1371/journal.pone.0093806 
Jia, H., Zhang, Y., Orbović, V., Xu, J., White, F. F., Jones, J. B., et al. (2017). Genome editing of the disease susceptibility gene CsLOB1 in citrus confers resistance to citrus canker. Plant Biotechnol. J. 15, 817-823. doi: 10.1111/pbi.12677

Jia, H.-F., Chai, Y.-M., Li, C.-L., Lu, D., Luo, J.-J., Qin, L., et al. (2011). Abscisic acid plays an important role in the regulation of strawberry fruit ripening. Plant Physiol. 157, 188-199. doi: 10.1104/pp.111.177311

Jiménez-Bermúdez, S., Redondo-Nevado, J., Muñoz-Blanco, J., Caballero, J. L., López-Aranda, J. M., Valpuesta, V., et al. (2002). Manipulation of strawberry fruit softening by antisense expression of a pectate lyase gene. Plant Physiol. 128, 751-759. doi: 10.1104/pp.010671

Jinek, M., Chylinski, K., Fonfara, I., Hauer, M., Doudna, J. A., and Charpentier, E. (2012). A programmable dual-RNA-guided DNA endonuclease in adaptive bacterial immunity. Science 337, 816-821. doi: 10.1126/science.1225829

Karlova, R., Chapman, N., David, K., Angenent, G. C., Seymour, G. B., and de Maagd, R. A. (2014). Transcriptional control of fleshy fruit development and ripening. J. Exp. Bot. 65, 4527-4541. doi: 10.1093/jxb/ eru316

Kaur, N., Alok, A., Shivani, Kaur, N., Pandey, P., Awasthi, P., et al. (2018). CRISPR/Cas9-mediated efficient editing in phytoene desaturase (PDS) demonstrates precise manipulation in banana cv. Rasthali genome. Funct. Integr. Genomics 18, 89-99. doi: 10.1007/s10142-017-0577-5

Kitagawa, M., Ito, H., Shiina, T., Nakamura, N., Inakuma, T., Kasumi, T., et al. (2005). Characterization of tomato fruit ripening and analysis of gene expression in F1 hybrids of the ripening inhibitor (rin) mutant. Physiol. Plant. 123, 331-338.

Klap, C., Yeshayahou, E., Bolger, A. M., Arazi, T., Gupta, S. K., Shabtai, S., et al. (2017). Tomato facultative parthenocarpy results from SlAGAMOUSLIKE 6 loss of function. Plant Biotechnol. J. 15, 634-647. doi: 10.1111/pbi. 12662

Kumar, R., Khurana, A., and Sharma, A. K. (2014). Role of plant hormones and their interplay in development and ripening of fleshy fruits. J. Exp. Bot. 65, 4561-4575. doi: 10.1093/jxb/eru277

Li, R., Fu, D., Zhu, B., Luo, Y., and Zhu, H. (2018). CRISPR/Cas9-mediated mutagenesis of lncRNA1459 alters tomato fruit ripening. Plant J. 160:595.

Li, X., Wang, Y., Chen, S., Tian, H., Fu, D., Zhu, B., et al. (2018). Lycopene is enriched in tomato fruit by CRISPR/Cas9-mediated multiplex genome editing. Front. Plant Sci. 9:559. doi: 10.3389/fpls.2018.00559

Liang, Z., Chen, K., Li, T., Zhang, Y., Wang, Y., Zhao, Q., et al. (2017). Efficient DNA-free genome editing of bread wheat using CRISPR/Cas9 ribonucleoprotein complexes. Nat. Commun. 8:14261. doi: $10.1038 /$ ncomms14261

Lor, V. S., Starker, C. G., Voytas, D. F., Weiss, D., and Olszewski, N. E. (2014). Targeted mutagenesis of the tomato procera gene using transcription activatorlike effector nucleases. Plant Physiol. 166, 1288-1291. doi: 10.1104/pp.114. 247593

Malnoy, M., Viola, R., Jung, M.-H., Koo, O.-J., Kim, S., Kim, J.-S., et al. (2016). DNA-free genetically edited grapevine and apple protoplast using CRISPR/Cas9 ribonucleoproteins. Front. Plant Sci. 7:1904. doi: 10.3389/fpls.2016. 01904

Malzahn, A., Lowder, L., and Qi, Y. (2017). Plant genome editing with TALEN and CRISPR. Cell Biosci. 7:21. doi: 10.1186/s13578-017-0148-4

Manning, K., Tör, M., Poole, M., Hong, Y., Thompson, A. J., King, G. J., et al. (2006). A naturally occurring epigenetic mutation in a gene encoding an SBPbox transcription factor inhibits tomato fruit ripening. Nat. Genet. 38, 948-952. doi: $10.1038 / \operatorname{ng} 1841$

Martin, S. E., and Caplen, N. J. (2007). Applications of RNA interference in mammalian systems. Annu. Rev. Genomics Hum. Genet. 8, 81-108. doi: 10.1146/annurev.genom.8.080706.092424

Martín-Pizarro, C., Triviño, J. C., and Posé, D. (2018). Functional Analysis of TM6 MADS Box Gene in the Octoploid Strawberry by CRISPR/Cas9 Directed Mutagenesis. bioRxiv [Preprint]. doi: 10.1101/351296

Meyer, R. S., and Purugganan, M. D. (2013). Evolution of crop species: genetics of domestication and diversification. Nat. Rev. Genet. 14, 840-852. doi: 10.1038/ $\operatorname{nrg} 3605$

Moxon, S., Jing, R., Szittya, G., Schwach, F., Rusholme Pilcher, R. L., Moulton, V., et al. (2008). Deep sequencing of tomato short RNAs identifies microRNAs targeting genes involved in fruit ripening. Genome Res. 18, 1602-1609. doi: $10.1101 /$ gr.080127.108
Nakajima, I., Ban, Y., Azuma, A., Onoue, N., Moriguchi, T., Yamamoto, T., et al. (2017). CRISPR/Cas9-mediated targeted mutagenesis in grape. PLoS One 12:e0177966. doi: 10.1371/journal.pone.0177966

Nishitani, C., Hirai, N., Komori, S., Wada, M., Okada, K., Osakabe, K., et al. (2016). Efficient genome editing in apple using a CRISPR/Cas9 system. Sci. Rep. 6:31481. doi: 10.1038/srep31481

Peng, A., Chen, S., Lei, T., Xu, L., He, Y., Wu, L., et al. (2017). Engineering cankerresistant plants through CRISPR/Cas9-targeted editing of the susceptibility gene CsLOB1promoter in citrus. Plant Biotechnol. J. 15, 1509-1519.

Perkins-Veazie, P. (1995). "Growth and ripening of strawberry fruit," in Horticultural Reviews, Vol. 17, ed. J. Janick (Oxford: John Wiley \& Sons, Inc.), 267-297. doi: 10.1002/9780470650585.ch8

Pnueli, L., Carmel-Goren, L., Hareven, D., Gutfinger, T., Alvarez, J., Ganal, M., et al. (1998). The SELF-PRUNING gene of tomato regulates vegetative to reproductive switching of sympodial meristems and is the ortholog of CEN and TFL1. Development 125, 1979-1989.

Posé, S., and García-Gago, J. A. (2011). Strawberry fruit softening: role of cell wall disassembly and its manipulation in transgenic plants. Genes Genomes 5, $40-48$.

Quesada, M. A., Blanco-Portales, R., Posé, S., García-Gago, J. A., JiménezBermúdez, S., Muñoz-Serrano, A., et al. (2009). Antisense down-regulation of the FaPG1 gene reveals an unexpected central role for polygalacturonase in strawberry fruit softening. Plant Physiol. 150, 1022-1032. doi: 10.1104/pp.109. 138297

Ren, C., Liu, X., Zhang, Z., Wang, Y., Duan, W., Li, S., et al. (2016). CRISPR/Cas9mediated efficient targeted mutagenesis in Chardonnay (Vitis vinifera L.). Sci. Rep. 6:32289. doi: 10.1038/srep32289

Robinson, R., and Tomes, M. (1968). Ripening inhibitor: a gene with multiple effectos on ripening. Tomato Genet. Coop. Rep. 18, 36-37.

Rodríguez-Leal, D., Lemmon, Z. H., Man, J., Bartlett, M. E., and Lippman, Z. B. (2017). Engineering quantitative trait variation for crop improvement by genome editing. Cell 171, 470-480.e8. doi: 10.1016/j.cell.2017.08.030

Ron, M., Kajala, K., Pauluzzi, G., Wang, D., Reynoso, M. A., Zumstein, K., et al. (2014). Hairy root transformation using Agrobacterium rhizogenes as a tool for exploring cell type-specific gene expression and function using tomato as a model. Plant Physiol. 166, 455-469. doi: 10.1104/pp.114.239392

Sheehy, R. E., Kramer, M., and Hiatt, W. R. (1988). Reduction of polygalacturonase activity in tomato fruit by antisense RNA. Proc. Natl. Acad. Sci. U.S.A. 85, 8805-8809. doi: 10.1073/pnas.85.23.8805

Smith, C. J., Watson, C. F., Morris, P. C., Bird, C. R., Seymour, G. B., Gray, J. E., et al. (1990). Inheritance and effect on ripening of antisense polygalacturonase genes in transgenic tomatoes. Plant Mol. Biol. 14, 369-379. doi: 10.1007/BF0002 8773

Smith, C. J. S., Watson, C. F., Ray, J., Bird, C. R., Morris, P. C., Schuch, W., et al. (1988). Antisense RNA inhibition of polygalacturonase gene expression in transgenic tomatoes. Nature 334, 724-726. doi: 10.1038/334724a0

Smith, D. L. (2002). Down-regulation of tomato beta -galactosidase 4 results in decreased fruit softening. Plant Physiol. 129, 1755-1762. doi: 10.1104/pp. 011025

Smith, J., Grizot, S., Arnould, S., Duclert, A., Epinat, J.-C., Chames, P., et al. (2006). A combinatorial approach to create artificial homing endonucleases cleaving chosen sequences. Nucleic Acids Res. 34:e149. doi: 10.1093/nar/gkl720

Soyk, S., Müller, N. A., Park, S. J., Schmalenbach, I., Jiang, K., Hayama, R., et al. (2016). Variation in the flowering gene SELF PRUNING 5G promotes day-neutrality and early yield in tomato. Nat. Genet. 49, 162-168.

Svitashev, S., Schwartz, C., Lenderts, B., Young, J. K., and Cigan, A. M. (2016). Genome editing in maize directed by CRISPR-Cas9 ribonucleoprotein complexes. Nat. Commun. 7, 1-7. doi: 10.1038/ncomms13274

Symons, G. M., Chua, Y.-J., Ross, J. J., Quittenden, L. J., Davies, N. W., and Reid, J. B. (2012). Hormonal changes during non-climacteric ripening in strawberry. J. Exp. Bot. 63, 4741-4750. doi: 10.1093/jxb/ers147

Tian, S., Jiang, L., Gao, Q., Zhang, J., Zong, M., Zhang, H., et al. (2016). Efficient CRISPR/Cas9-based gene knockout in watermelon. Plant Cell Rep. 36, 399-406. doi: 10.1007/s00299-016-2089-5

Tieman, D. M., and Handa, A. K. (1994). Reduction in pectin methylesterase activity modifies tissue integrity and cation levels in ripening tomato (Lycopersicon esculentum Mill.) Fruits. Plant Physiol. 106, 429-436. doi: $10.1104 /$ pp.106.2.429 
Tieman, D. M., Harriman, R. W., Ramamohan, G., and Handa, A. K. (1992). An antisense pectin methylesterase gene alters pectin chemistry and soluble solids in tomato fruit. Plant Cell 4, 667-679. doi: 10.1105/tpc. 4.6.667

Ueta, R., Abe, C., Watanabe, T., Sugano, S. S., Ishihara, R., Ezura, H., et al. (2017). Rapid breeding of parthenocarpic tomato plants using CRISPR/Cas9. Sci. Rep. 7:507. doi: 10.1038/s41598-017-00501-4

Uluisik, S., Chapman, N. H., Smith, R., Poole, M., Adams, G., Gillis, R. B., et al. (2016). Modulation of tomato fruit texture by silencing cell wall structurerelated genes. Nat. Biotechnol. 34, 950-952.

Urnov, F. D., Miller, J. C., Lee, Y.-L., Beausejour, C. M., Rock, J. M., Augustus, S., et al. (2005). Highly efficient endogenous human gene correction using designed zinc-finger nucleases. Nature 435, 646-651. doi: 10.1038/nature 03556

Van Eck, J., Kirk, D. D., and Walmsley, A. M. (2006). Tomato (Lycopersicum esculentum). Methods Mol. Biol. 343, 459-473. doi: 10.1385/1-59745-130-4:459

Vrebalov, J., Ruezinsky, D., Padmanabhan, V., White, R., Medrano, D., Drake, R., et al. (2002). A MADS-box gene necessary for fruit ripening at the tomato ripening-inhibitor (rin) locus. Science 296, 343-346. doi: 10.1126/science. 1068181

Wang, X., Ai, G., Zhang, C., Cui, L., Wang, J., Li, H., et al. (2016). Expression and diversification analysis reveals transposable elements play important roles in the origin of Lycopersicon-specific lncRNAs in tomato. New Phytol. 209, 1442-1455. doi: 10.1111/nph.13718

Wang, Z., Wang, S., Li, D., Zhang, Q., Li, L., Zhong, C., et al. (2018). Optimized paired-sgRNA/Cas9 cloning and expression cassette triggers high-efficiency multiplex genome editing in kiwifruit. Plant Biotechnol. J. 16, 1424-1433. doi: $10.1111 /$ pbi. 12884
Woo, J. W., Kim, J., Kwon, S. I., Corvalán, C., Cho, S. W., Kim, H., et al. (2015). DNA-free genome editing in plants with preassembled CRISPR-Cas9 ribonucleoproteins. Nat. Biotechnol. 33, 1162-1164. doi: 10.1038/nbt.3389

Yang, Y., Zhu, G., Li, R., Yan, S., Fu, D., Zhu, B., et al. (2017). The RNA editing factor SlORRM4 is required for normal fruit ripening in tomato. Plant Physiol. 175, 690-702. doi: 10.1104/pp.17.01265

Yu, Q.-H., Wang, B., Li, N., Tang, Y., Yang, S., Yang, T., et al. (2017). CRISPR/Cas9induced targeted mutagenesis and gene replacement to generate long- shelf life tomato lines. Sci. Rep. 7:1874. doi: 10.1038/s41598-017-12262-1

Zhou, J., Wang, G., and Liu, Z. (2018). Efficient genome-editing of wild strawberry genes, vector development, and validation. Plant Biotechnol. J. doi: 10.1111/pbi. 12922 [Epub ahead of print].

Zhu, B., Yang, Y., Li, R., Fu, D., Wen, L., Luo, Y., et al. (2015). RNA sequencing and functional analysis implicate the regulatory role of long non-coding RNAs in tomato fruit ripening. J. Exp. Bot. 66, 4483-4495.

Zhu, Q.-H., and Wang, M.-B. (2012). Molecular functions of long non-coding RNAs in plants. Genes 3, 176-190. doi: 10.3390/genes3010176

Conflict of Interest Statement: The authors declare that the research was conducted in the absence of any commercial or financial relationships that could be construed as a potential conflict of interest.

Copyright (c) 2018 Martín-Pizarro and Posé. This is an open-access article distributed under the terms of the Creative Commons Attribution License (CC BY). The use, distribution or reproduction in other forums is permitted, provided the original author(s) and the copyright owner(s) are credited and that the original publication in this journal is cited, in accordance with accepted academic practice. No use, distribution or reproduction is permitted which does not comply with these terms. 